\title{
A PERFORMATIZAÇÃO DE MASCULINIDADES NAS CAPAS DE SUI GENERIS (1995-2000)
}

THE PERFORMATIZATION OF MASCULINITIES

ON THE COVERS OF SUI GENERIS (1995-2000)

LA PERFORMATIZACIÓN DE MASCULINIDADES

EN LAS PORTADAS DE SUI GENERIS (1995-2000)

\section{RICARDO AUGUSTO DE SABÓIA FEITOSA ${ }^{1}$}

\section{ALMUDENA GARCÍA MANSO²}

${ }^{1}$ Doutor em Sociologia pela Universidade Federal do Ceará (UFC).

Professor Adjunto da Universidade Federal de Pernambuco (UFPE).

ORCID iD: https://orcid.org/0000-0002-4095-5165

${ }^{2}$ Doutora em Sociologia pela Universidade da Salamanca (Espanha).

Professora de Ciências da Comunicação na Universidad Rey Juan Carlos (Espanha).

ORCID iD: https://orcid.org/0000-0002-8781-5020

\section{RESUMO}

O artigo propõe, a partir de uma leitura crítica de 12 capas publicadas pela revista Sui Generis entre os anos de 1995 e 2000, analisar a construção discursiva (imagético e textual) das masculinidades, interrogando quais representações do masculino são ali encenadas, reiteradas ou deslocadas. Entende-se que esse conjunto permite refletir criticamente sobre como as masculinidades performadas na publicação inserem-se em processos de negociações e reelaborações editoriais e sociais que, no contexto de uma revista endereçada majoritariamente a uma audiência gay masculina, estão interrelacionadas a processos mais amplos de visibilização e cenarização pública das homossexualidades no Brasil na virada do último século.

Palavras-chave: Masculinidades. Homossexualidades. Jornalismo. Gênero 


\begin{abstract}
The article offers, from a critical reading of 12 covers published by the magazine Sui Generis between 1995 and 2000, it analyzes the discursive construction (imagery and text) of masculinities, questioning which representations of the masculine are staged, reiterated or displaced. It is understood that this set allows to reflect critically on how the masculinities performed in the publication are inserted in processes of transformation and editorial and social re-elaborations that, in the context of a magazine addressed mainly to a male gay audience, are processes interrelated to more public visibility and scenarios for homosexuality in Brazil at the turn of the last century.
\end{abstract}

Keywords: Masculinities. Homosexualities. Journalism. Genre

\title{
RESUMEN
}

El artículo propone, a partir de una lectura crítica de 12 portadas publicadas por la revista Sui Generis entre 1995 y 2000, analizar la construcción discursiva (imágenes y texto) de las masculinidades, cuestionando qué representaciones de lo masculino se escenifican, reiteran o desplazan allí. Se entiende que este conjunto nos permite reflexionar críticamente sobre cómo las masculinidades realizadas están insertadas en procesos de negociaciones y reelaboraciones editoriales y sociales que, en el contexto de una revista dirigida principalmente a un público masculino gay, están interrelacionadas con procesos más amplios de visibilidad y performatización pública de la homosexualidad en Brasil a finales del siglo pasado y princípios del siglo XXI.

Palabras-clave: Masculinidades. Homosexualidades. Periodismo. Género

\section{INTRODUÇÃO}

A atenção conferida às masculinidades como construção sociocultural chave na organização de nossas relações e políticas de gênero e sexualidades, das relações de poder e sua articulação com o patriarcado ocupou, em décadas recentes, posição destacada em investigações acadêmicas que abrangem desde o campo dos estudos LGBTs aos feminismos, estudos de mídia etc. Debates sobre "ser homem”, “o que é o masculino?”, “quais características teria o 'novo homem'?” ilustram inquietações que também têm 
atravessado conversas informais, ativismos, reportagens de jornais e televisão, o cotidiano nas escolas ou nos espaços de lazer e sociabilidade.

Uma vez que as masculinidades não se configuram exclusivamente como sinônimo de práticas e relações de e entre "homens", há a necessidade de reconhecer não apenas a existência de masculinidades no plural, mas de pôr em perspectiva crítica as potencialidades e os limites dessa pluralidade. De quais masculinidades estamos falando? Quais masculinidades ousamos repensar?

Connell e Messerschmidt (2013) sugerem, mediante revisão do conceito de "masculinidade hegemônica", atualizar o debate frente a "novas dinâmicas das masculinidades". Assim, ressaltam que "devemos reconhecer agora explicitamente a estratificação, a potencial contradição interna, dentre todas as práticas que constroem masculinidades". Faz-se necessário situá-las "nas arenas globais das corporações transnacionais, das mídias e dos sistemas de segurança" onde "novos padrões de hegemonia estão sendo forjados" (2013, p.274).

Outro nome que se tornou referência na área, Kimmel (2008) destaca que "temos que falar de como diferentes culturas representam a masculinidade de diferentes maneiras através da arte, da literatura, da música, do cinema e de qualquer outro tipo de meio de comunicação" (p. 17; tradução livre). Não obstante, tais representações são (re)elaboradas em contextos históricos, culturais, raciais, sociais e de gênero específicos e, ao mesmo tempo, numa dinâmica em que se destaca a atuação dos meios de comunicação.

Assim, é importante compreender as masculinidades como processos socioculturais em contínua elaboração, entre reiterações e desconstruções. Elas são, na perspectiva de Woodward (2007, p. 38), “forjadas através de redes e associações" formais e informais, como a mídia, locais de sociabilidade esportivos, os fóruns de internet etc., espaços onde "é possível pactuar com versões particulares da masculinidade ou ainda resistir a elas"1. Analisando mais especificamente como a prática esportiva do boxe configura a criação e

${ }^{1}$ Tradução nossa. As citações extraídas de textos em idioma estrangeiro foram traduzidas, neste artigo, pelos autores. 
recriação de masculinidades, nos processos de socialização e (re)elaborações do self, a autora (2007, p. 3) nos lembra que as masculinidades não existem num terreno cultural separado, mas coexistem com outras identificações e outras versões de elaborações de si”. Ressaltamos este aspecto para enfatizar que, não obstante o interesse pelas "novas masculinidades", sua crise contemporânea ou novas configurações, estas se correlacionam e coexistem, não sem conflitos e tensões, como demonstraremos na análise das capas de Sui Generis, com uma "resiliência de masculinidades tradicionais (...) associadas à marcação das diferenças de gênero e aos modos com que corpos são inscritos através de aparelhos de classificação, que são poderosamente "encorporados" (Woodward, 2007, p. 14).

Diante desse reconhecimento e da relevância do tema, busca-se analisar neste artigo como uma revista endereçada majoritariamente a um público gay urbano e de classe média/alta no Brasil dos anos 1990, performava e conferia visibilidade a determinados modos de representar masculinidades. Quando dizemos que tais masculinidades eram performadas, ecoamos a perspectiva de Butler que, ao situar a noção de performance repetida para caracterizar o processo mais amplo de construção e desconstrução do gênero como ato, define esta como "a um só tempo reencenação e nova experiência de um conjunto de significados já estabelecidos socialmente" (p. 242), sendo o gênero "uma identidade tenuamente constituída no tempo, instituído num espaço externo por meio de uma repetição estilizada de atos" (grifo da autora, p. 242). Destaca também,

$\mathrm{O}$ fato de a realidade do gênero ser criada mediante performances sociais contínuas significa que as próprias noções de sexo essencial e de masculinidade ou feminilidade verdadeiras ou permanentes também são constituídas, como parte estratégica que oculta o caráter performativo do gênero e as possibilidades performativas de proliferação das configurações de gênero fora das estruturas restritivas da dominação masculinista e da heterossexualidade compulsória (Butler, 2016, p. 244).

Igualmente importante para nossa investigação, notadamente na articulação dos domínios da masculinidades e da produção dos discursos jornalísticos e midiáticos, foi recuperar a perspectiva de De Lauretis (1994) ao tratar das "tecnologias de gênero", em que 
a mídia, assim como a escola, os tribunais, as artes, a família, a academia etc., é tomada como um artefato relevante de reprodução, agenciamento, construção e desconstrução das identidades e relações sexuais e de gênero, sendo este assim concebido por ela como "uma representação". Esta representação, porém, além de ter fundamentalmente "implicações concretas ou reais (...), tanto sociais quanto subjetivas, na vida material das pessoas", implica em reconhecer que "a representação do gênero é a sua construção" e que, "paradoxalmente, (...) a construção do gênero também se faz por meio de sua desconstrução", de modo que

o gênero, como o real, é não apenas o efeito da representação, mas o seu excesso, aquilo que permanece fora do discurso como um trauma potencial que, se/quando não contido, pode romper ou desestabilizar qualquer representação" (DE LAURETIS, 1994, p. 209).

Ressaltamos ainda que a escolha desta revista está associada à sua influência num contexto particular, de meados para final do século passado. Produzida numa pequena redação da zona sul do Rio de Janeiro, com colaboradores de outros centros urbanos e o anseio de circular, via assinatura ou venda em bancas de revista, nacionalmente, Sui Generis é classificada pelo antropólogo Richard Parker (2002) como "uma das mais sofisticadas e visíveis dessa nova onda" de "revistas e jornais gays" (p.337) do período e, considerando a volatilidade com que muitas publicações apareciam e saíam rapidamente de cena, uma experiência jornalística bem-sucedida, mesmo frente às inúmeras dificuldades editoriais e comerciais enfrentadas ao longo de seus cinco anos.

Selecionamos, a partir de uma leitura prévia, 12 edições de 55 publicadas por Sui Generis entre 1995 e 2000. A leitura inicial do conjunto de todas as capas permitiu uma visão mais panorâmica da revista como empreendimento editorial, identificando elementos imagéticos e textuais recorrentes, algumas temáticas e enquadramentos privilegiados que iam desde a relativa recorrência de determinados modelos de homens retratados na primeira página às chamadas textuais de cada edição. Igualmente, buscou-se observar as capas que 
pareciam, ainda nesse primeiro olhar, destoar da escolha por homens no geral fortes, "saudáveis", jovens, viris, enquadrados em determinados padrões de beleza etc. ou que sugeriam, como hipótese exploratória, outras aberturas de visibilização e performatização do masculino.

Dessa primeira leitura, selecionamos então as 12 edições modelares, isto é, que permitiriam aprofundar as questões analíticas propostas. Buscamos, nos limites em que uma operação dessa ordem incorre, manter nesse conjunto mais delimitado, uma representatividade do que entendemos ser as bases da proposta editorial, cultural e mercadológica da revista Sui Generis, em sua diversidade, pluralidade, mas também em suas limitações, contradições e "desvios". Lembramos ainda que, para este trabalho específico, o critério de seleção foi o diálogo com a questão das masculinidades. Neste recorte, também foi levado em conta edições que abrangessem diferentes anos no intervalo entre 1995 e 2000, de modo a contemplar as eventuais recorrências, deslocamentos, amadurecimento e mudanças editoriais ao longo de toda a trajetória de existência da revista.

Como estratégia metodológica principal, adotou-se a análise discursiva (AD) das imagens e textos que compõe as capas selecionadas, seguindo a perspectiva de Verón que "todo discurso tem duas faces: remete, por um lado, às suas condições de engendramento; é, por outro lado, um exercício de poder". Assim, ao analisar os discursos elaborados nas primeiras páginas de Sui Generis, buscamos identificá-los como "o lugar de mediação entre um universo de operações e um universo de representações” (VERÓN, 1980, p. 217-218) de produção de masculinidades.

Em estudo específico sobre a produção da masculinidade em três revistas brasileiras no final da década de 1990, incluindo Sui Generis, Monteiro (2000) ressalta que esta privilegia em suas páginas determinado modelo de homem gay:

Na sua busca de elevar a autoestima de um público marginalizado, a revista constrói um referencial de estilo de vida para o gay moderno que passa em larga escala pelo consumo diferenciado (de cultura e de "produtos gays"), pela 
preocupação com a aparência e pelo cultivo de um corpo masculino, malhado e regulado (p. 138)

Concordamos que, em linhas gerais, a revista investe numa imagem positiva do homem gay como consumidor, mas a partir de nosso corpus mais restrito, procuramos interrogar a recorrência de determinados modelos identificados em suas capas, assim como exemplos que pudessem sugerir outras possibilidades de leitura e abordagens das masculinidades. Assim, são lidas em diálogo, que ora podem revelar afinidades e complementaridades, ora nos interrogam acerca de eventuais tensões e deslocamentos. A escolha por uma leitura discursiva das primeiras páginas decorre desta ser, como destacam Vaz e Trindade (2013, p. 225), "a vitrine de qualquer publicação". Os autores entendem que "cabe à capa, portanto, o papel de traduzir as intenções, o posicionamento e a identidade da revista", convertendo-se num "canal de comunicação constante com o leitor, permitindo que, antes mesmo de folhear a revista, ela saiba do que ela fala e como fala" (Ibid).

\section{MASCULINIDADES SUI GENERIS?}

A partir do corpus, desdobram-se leituras que permitem explorar as articulações emergentes entre a produção discursiva (verbal e imagética) dessas capas, as políticas editoriais associadas a visibilidades de sujeitos e corpos específicos, em consonância com a projeção de um público leitor preferencial, e a produção específica de masculinidades numa revista projetada como gay.

A primeira edição (janeiro de 1995) é significativa para explorarmos como a capa pode sintetizar e ao mesmo abrir brechas para discutir essas políticas. Em primeiro plano, vê-se a figura de um cantor pop internacionalmente conhecido. Em outro lugar (AUTOR, 2018), discutiu-se em que medida a escolha dessa personagem para ilustrar pode ser lida no interior de um projeto de Sui Generis se colocar como uma revista que retratasse determinado perfil de uma "comunidade" e "identidade" gay apresentada como antenada, 
vibrante, positiva e globalizada. Reiteramos que a ênfase aqui é amplamente centrada na "saída do armário" do cantor, explicitada na manchete "I am gay", antecedida pelo anúncio de que este "abre o jogo" (Figura 1).

Evidentemente, a "revelação" do artista enquadra-se nos princípios básicos de valornotícia ${ }^{2}$ como elemento essencial do jornalismo (o cantor “assumir" ser gay publicamente), mas nos cabe interrogar como discursivamente é elaborado o "jogo" performado nesta capa. Há na composição o recurso tradicional de o retratado mirar diretamente ao leitor. Neste contexto, serve para reforçar que o ato do coming out representa uma partilha de sua própria intimidade, uma confissão também para o leitor, reiterando, assim, a construção da revista como um veículo "gay" e para "gays". Entendemos que a primeira leitura do gestual, em que o artista estar desabotoando a camisa, associa o que é anunciado verbalmente ("sou gay") ao ato de despir-se, desnudar-se, tudo isso aos olhos de um público, como se supõe uma "saída do armário".

Ao mesmo tempo, como a imagem é um instante desse gestual ${ }^{3}$, acreditamos haver espaço para uma segunda leitura: e se pudermos ver esse detalhe da cena de modo inverso, como a captura do cantor reabotoando a camisa, instantes após ter se despido ao leitor, e de ter feito justamente uma confissão ${ }^{4}$ ? A ideia de "jogo" mencionada no título assim pode ser situada nas próprias implicações do outing, entre público (cantor e os leitores/ "comunidade gay" /sociedade) e privado (o cantor e cada leitor, unidos nessa situação íntima).

\footnotetext{
2 Traquina (2008) define "valor-notícia" como procedimento de seleção e transformação de acontecimentos em notícias, mediante o cumprimento de uma série de critérios (como simplificação e personificação dos fatos, dramatização de eventos, a novidade etc.). Tais critérios não são necessariamente fixos, pois um ou outro aspecto do valor-notícia pode ser privilegiado segundo o perfil de cada publicação.

${ }^{3}$ Barthes (2015) fala de punctum como um "detalhe", "acaso", "pequeno corte”, "uma espécie de extracampo sutil, como se a imagem lançasse o desejo para além daquilo que ela dar a ver" (p. 42, 53).

${ }^{4}$ É bastante conhecida a associação empreendida por Foucault (1999) entre a confissão e os processos de "colocação do sexo em discurso: "Coloca-se um imperativo: não somente confessar os atos contrários à lei, mas procurar fazer de seu desejo, de todo o seu desejo, um discurso" (p.24).
} 

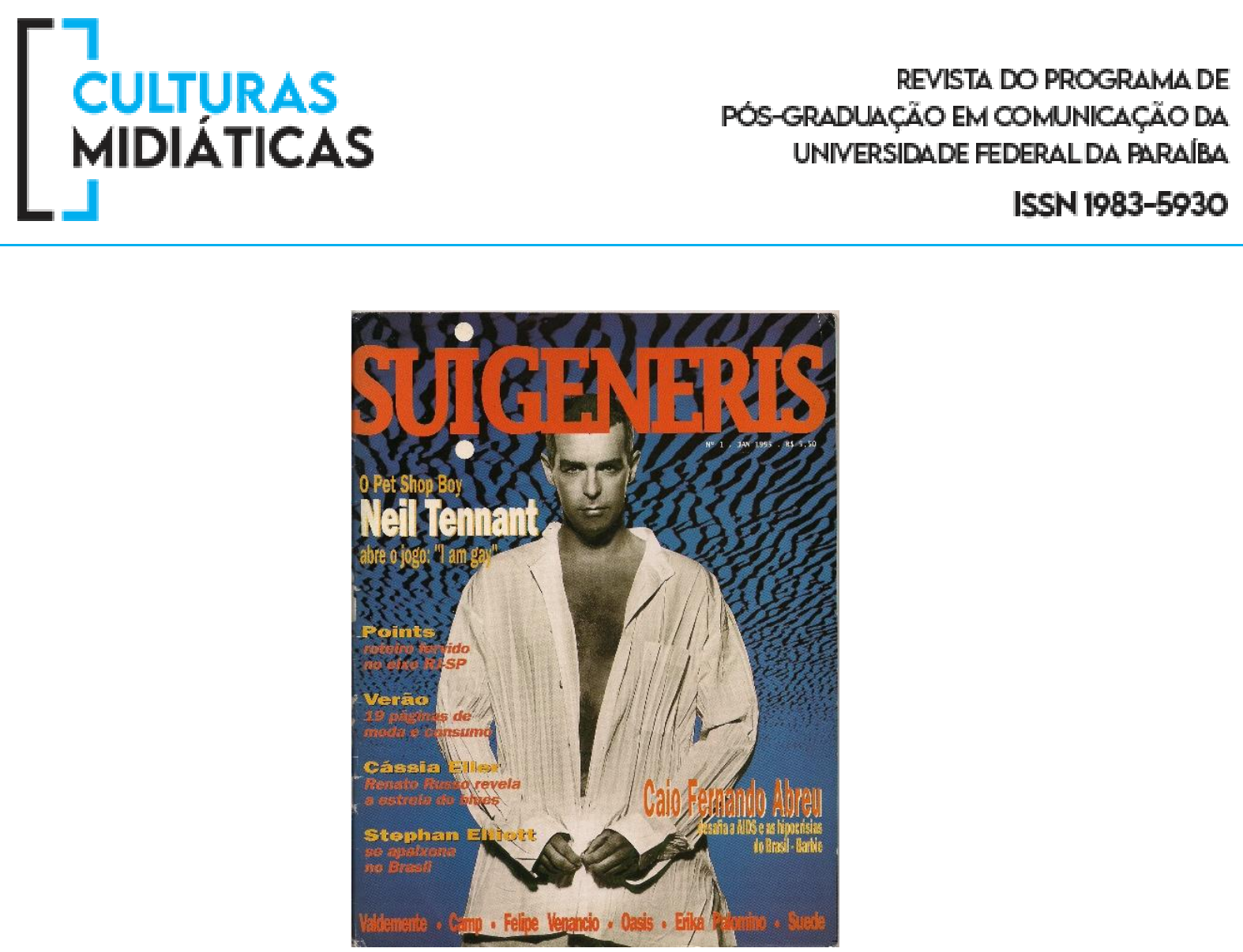

Figura 1 - Sui Generis, n. 1 Fonte: autor.

Esse jogo fica mais interessante quando se olha para a chamada de outra entrevista presente naquela edição, em que o escritor Caio Fernando Abreu é apresentado desafiando a "AIDS e as hipocrisias do Brasil-Barbie". Cabe lembrar que a "Barbie" se destaca, como categoria no universo LGBT do Brasil de meados dos anos 90, simbolizando um modelo de masculinidade centrado no culto ao corpo hipertrofiado, marcado pela ausência de pelos, higienizado, "limpo", "saudável, trabalhado nas academias de ginástica e exibido em festas

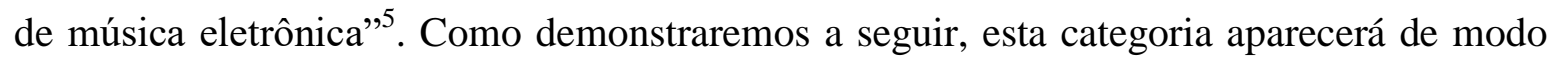
recorrente nas edições de Sui Generis, ora em suas capas, ora em fotos internas que ilustravam reportagens, editoriais de moda, cobertura de festas noturnas, etc.

Na edição 25 (Figura 2), de julho de 1997, a capa repete o artifício tradicional de apresentar um modelo encarando o leitor. Temos, aqui, um plano que valoriza a exposição do corpo, na indumentária restrita a um traje de banho branco que põe em evidência

\footnotetext{
5 Para uma leitura da "Barbie" como categoria/modelo presente no universo gay brasileiro da época, cf. Gontijo (2009).
} 


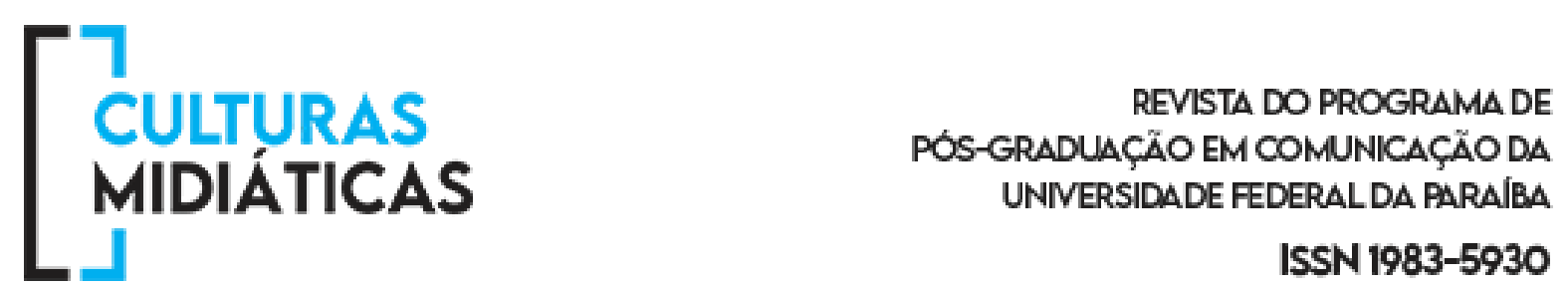

justamente as características do "corpo-barbie": liso, barba feita, rosto anguloso, cabelo curto bem delineado, bíceps, coxas, abdômen e peitoral definidos. O modo sério com que o modelo fixa a mirada tenta manter a imagem no domínio da virilidade, dissociando-se este homem de qualquer associação ao "afeminamento" ou à feminilidade.

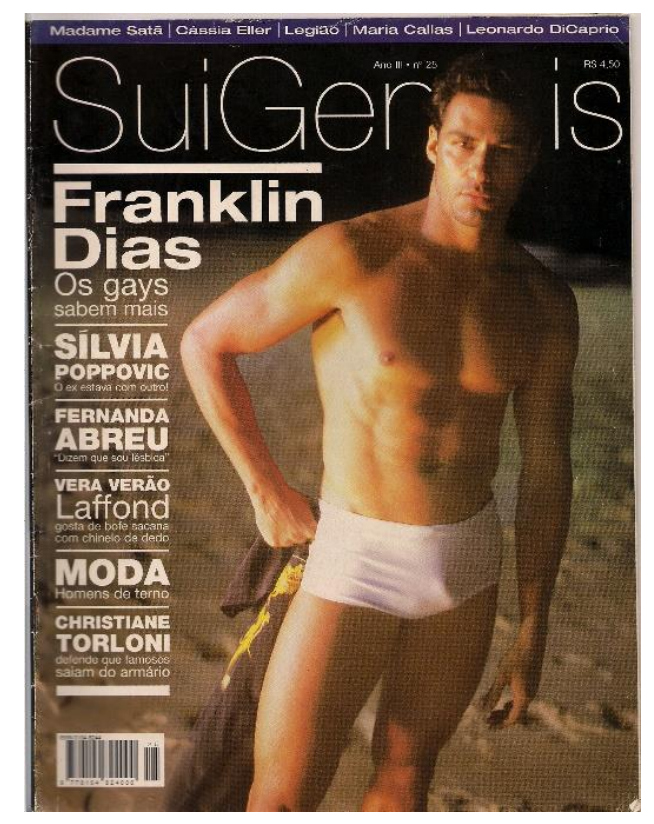

Figura 2 - Sui Generis, n. 25.

Fonte: o autor.

Mas cabe, novamente, buscar o diálogo da imagem com os demais elementos textuais que compõem a capa, em particular com a manchete "Vera Verão/Laffond gosta de bofe sacana com chinelo de dedo", em que se registra um outro modelo de masculinidade, a do "bofe", categoria recorrente para definir o homem rude, viril, geralmente peludo, associado (e valorizado) a uma masculinidade normativa ${ }^{6}$. Não obstante, o ator Jorge Laffond era

\footnotetext{
${ }^{6}$ No campo dos estudos de sexualidade e gênero no Brasil, é considerado clássico o ensaio de Peter Fry (1982) em que se propõe a "investigar a construção das categorias sociais que dizem respeito à sexualidade no Brasil", como a construção de categorias como bicha e bofe. Contudo, é preciso não enquadrar essas categorias como fixas, como modelos. Como destacam Simões e Facchini (2009), "A insistência no termo 'modelo' é crucial para situar com mais clareza o plano em que essa leitura se situa: isto é, o plano das ideias, valores, representações e categorias sociais por meio dos quais procuramos tornar inteligíveis
} 


\section{[CuLTURAS MIDIÁTICAS

conhecido na cena midiática brasileira ao encarnar a personagem Vera Verão num programa popular humorístico, em esquetes que costumavam encenar situações em que ele representava a "bicha" disputando os homens com outras mulheres.

Esse modelo do "bofe" é explorado nas edições 10 (março de 1996) e 19 (janeiro de 1997), estampadas por duas personalidades, o jogador de futebol Renato Gaúcho e o ator Alexandre Frota, respectivamente (Figuras 3 e 4).

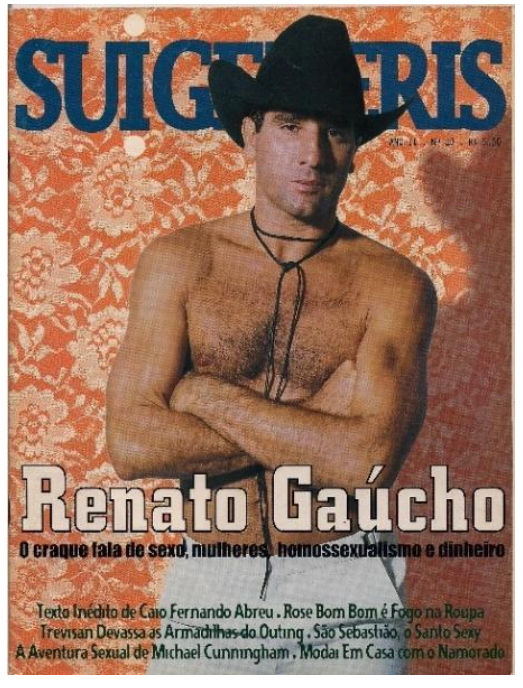

Figura 3 - Sui Generis, n. 10 Fonte: o autor.

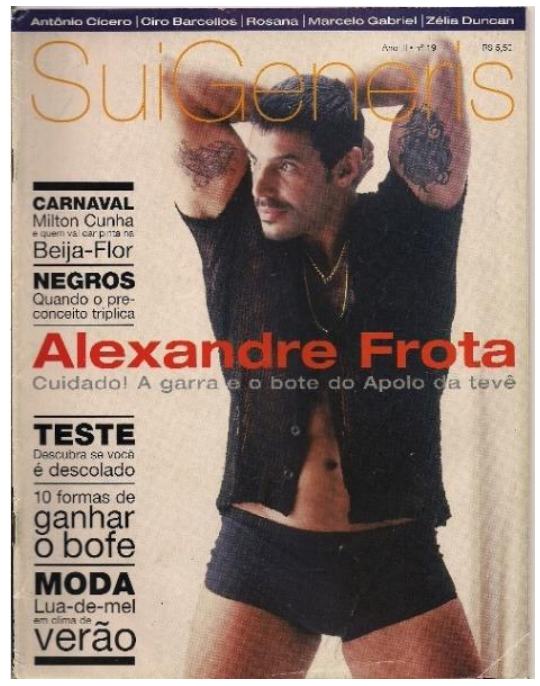

Figura 4 - Sui Generis, n. 19 Fonte: o autor.

Nas duas capas, há ênfase no corpo viril. No primeiro caso, a personagem em questão traz o próprio imaginário do futebol como um universo majoritariamente masculino, em que jogadores bem-sucedidos ("o craque") teriam acesso a "sexo", "mulheres" e "dinheiro", expressões que compõem a manchete. Contextualmente, essa imagem deve ser lida considerando o jogador ter sido um rosto conhecido na década anterior (1980), quando atuou em clubes de futebol de grande popularidade, construindo-se em torno dele uma imagem de "garanhão".

comportamentos e identidades. Entre esse plano [...] e o plano das condutas e das identidades sexuais de gênero efetivamente acionadas, há inconsistências, conflitos e margens de manobra para os atores sociais" (p.58 e 59). 
Entendemos que o modo como se performa naquele espaço, a virilidade envolve, assim, a recorrência de signos como a exibição dos pelos corporais e o chapéu de caubói, acionando um modelo de macho que teve relativa popularidade em certo imaginário gay pop de fins de anos 1970 e de boa parte da década posterior. Tal associação, por sua vez, parece não ultrapassar os limites que circunscreveriam aquele corpo ao domínio da heterossexualidade. Assim, também fica em primeiro plano a pose encenada pelo jogador, de braços cruzados. Ao mesmo tempo em que permite salientar seus músculos (bíceps, ombros, peitoral), à disposição da fruição erótica do leitor, também serve como interdição dos limites deste "acesso", como se lhe dissesse "pode-se olhar, mas deste ponto não se pode passar". Não por acaso, a disposição dos termos "sexo" e "mulheres" acompanham o "homossexualismo" ( $\mathrm{sic}$ ) como um dos temas abordados, o que sugere uma negociação para conseguir emplacar na capa de uma revista gay um jogador de futebol famoso, desde que preserve a posição relativamente segura de reiteração de sua heterossexualidade ${ }^{7}$.

A edição 19 também investe em outro nome famoso dos anos 1980, o ator Alexandre Frota, que no final daquela década encarnou numa telenovela de sucesso Apolo, um homem forte, viril, pertencente ao núcleo das classes populares, em contraponto a outro personagem de classe alta, um publicitário yuppie, com quem disputava o amor da protagonista. Desse modo, a chamada textual o caracterizando como "o Apolo da TV" aciona também a memória do leitor sobre essa representação anterior.

Há, na pose do fotografado, a recorrência a uma certa tradição de fotografia homoerótica, enfatizando a força física e a plástica de movimentos. Oliva (2007) nos lembra que a recorrência de citações à Antiguidade Clássica constitui-se num recurso importante como "subterfúgio" para legitimar ou "tornar aceitáveis" imagens fotográficas

\footnotetext{
${ }^{7}$ Na década de 1980, a imprensa esportiva passou a especular sobre a relação de amizade de Renato Gaúcho com outro jogador, Leandro. Este episódio é analisado, numa perspectiva que cruza o futebol e a produção/reiteração de masculinidades, por Pacheco (2014): "Renato era retratado pela imprensa como um jogador impulsivo, individualista, driblador, contestador, provocador, 'maluco', sedutor e incontrolável", enquanto "Leandro era retratado como um homem sensível, tímido e introvertido [...] Se há um atleta que se aproxima da masculinidade hegemônica dominante é Renato, pois ele é representado como um homem confiante, que desafia outros homens e é conquistador, sedutor de mulheres (p.6).
} 
de homens nus, intimamente associadas ao nascimento da fotografia no século XIX, mas que se prolonga com frequência pelo menos até meados dos anos 1970, seja como "subterfúgio" ou como "clichê estético" (p. 417; tradução livre). Este modo de salientar a forma física do corpo masculino também foi expressivo em certa tradição que ganha proeminência nos anos 1950, com revistas associando o corpo masculino ao fisiculturismo, em publicações que, como demonstra Leddick (2018), criaram toda uma subcultura centrada na circulação dessas revistas tendo como público prioritário uma "clientela homossexual" (p. 216).

Ao mesmo tempo em que tais referências são recuperadas, algo que pode ser visto nos braços abertos que reforçam a proeminência dos bíceps e a valorização do abdômen do ator, há outros elementos que atualizam esta representação e, por sua vez, de uma masculinidade associada ao "bofe", como o uso pelo ator de uma corrente de ouro. Reiterase o vínculo virilidade-masculinidade-personagem, mas entendemos que nesta imagem, se não há uma subversão das premissas desse conjunto, também este é explorado de modo mais irônico ou deslocado: a camisa em tecido transparente, a blusa aberta na altura do abdômen, os braços abertos para uma maior contemplação do leitor, toda a cena registrada num fundo dominado por uma cortina branca, sugerindo que a foto foi realizada em um quarto, local por excelência de intimidade. Aqui, é preciso novamente ver o diálogo com a chamada textual, em que as expressões "garra" e "bote" antecedidas do alerta "Cuidado!" sugerem um homem "ativamente" possível ao interesse do leitor. Igualmente relevante é olhar para a capa em sua totalidade, em que podemos destacar a chamada para uma outra reportagem, "10 formas de ganhar o bofe". "Ganhar o bofe" aparece graficamente de modo mais destacado, reforçando o vínculo daquele corpo masculino a este referencial.

A edição 20 (fevereiro de 1997) traz como principal destaque a reportagem "Garotos de Programa - Depois das drags, eles vão invadir a sua vida” (Figura 5). 

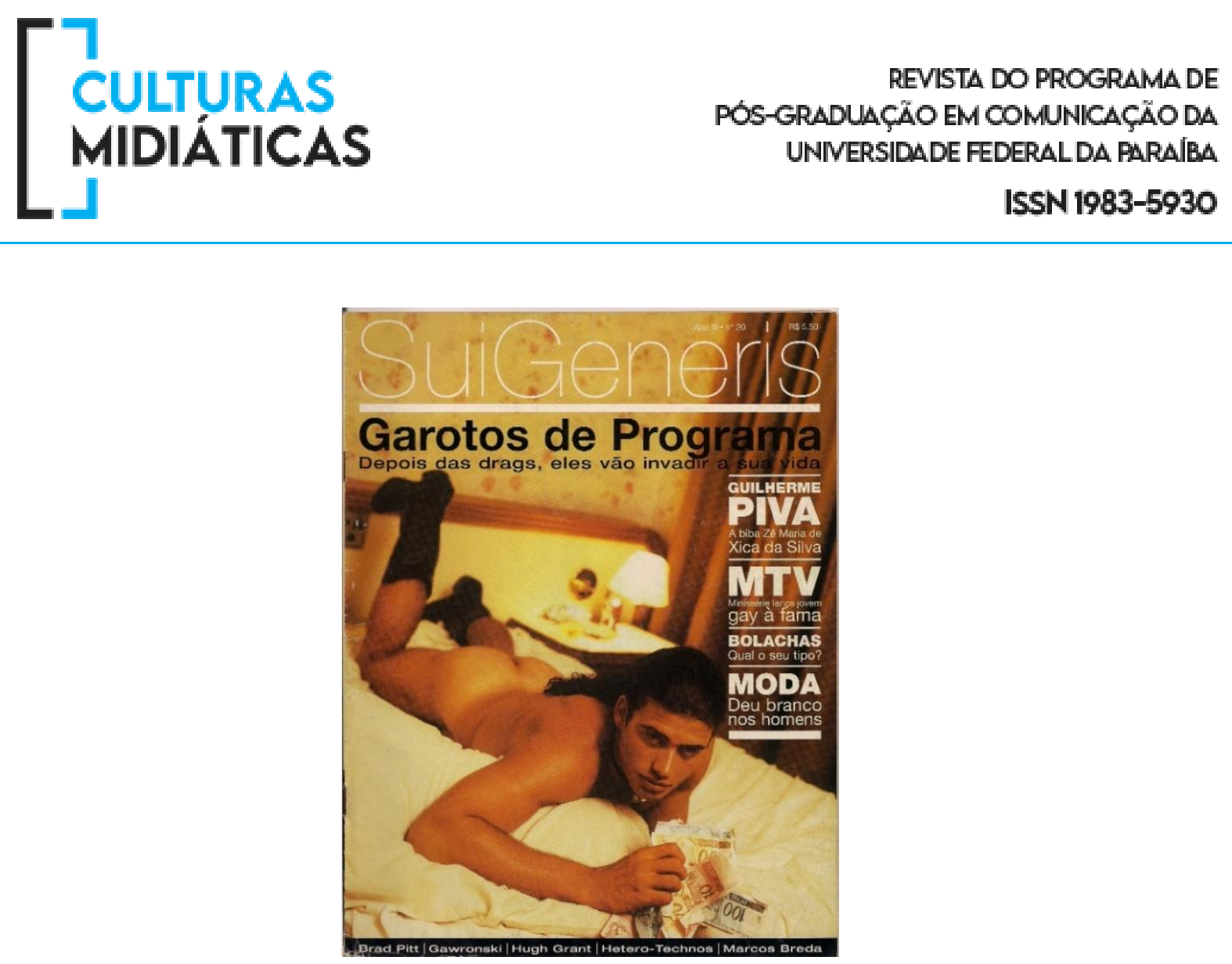

Figura 5 - Sui Generis, n. 20 Fonte: o autor

A composição reforça associações a um modelo que encarna uma masculinidade valorizada no imaginário de uma (sub)cultura gay de consumo, como na capa da edição 10, e a única vestimenta identificável é um par de botas de caubói. Mas estas aparecem aqui, numa versão mais modernizada, em sintonia com a cobertura de moda da revista de então, um dos diferenciais de Sui Generis. O cenário remete a um quarto de motel, em que os elementos de decoração reforçam essa associação (botões na cabeceira da cama, papel de parede etc.). Um calhamaço de cédulas nas mãos do modelo não apenas reitera visualmente o que a manchete já explicitava como tema da reportagem, mas também a relação estabelecida entre o leitor que olha e compra aquelas imagens e a fantasia de contratar um "michê".

Repete-se o gesto recorrente de o modelo encarar o leitor. Aqui, a própria temática centrada nos "garotos de programa" permite recuperar a figura destes como uma imagem masculina de desejo, abrindo para debate a própria questão da representação desta em 
correlação à relações de poder estabelecidas entre modelo/leitor, michê-cliente, profissional-consumidor.

O modelo, assim, carrega símbolos em sintonia com a imagem do garoto de programa atrativa ao leitor de Sui Generis, mas com uma nova imagem, mais moderna, sofisticada do que aquela associada ao garoto de programa das ruas: bronzeado, ombros definidos, nariz, boca e queixos harmônicos. Não obstante, a reportagem trata deste novo modelo de michê como um "fenômeno", uma novidade disponível aos homens gays. Invadir "sua vida", neste caso, é invadir o universo deste leitor consumidor idealizado e contemporâneo. O modelo retratado, por sua vez, incita e ao mesmo tempo regula eroticamente esta relação.

Estratégia similar a essa de, a partir de um "gancho jornalístico" que oferecia ao leitor reportagem comportamental de temática de seu interesse, elaborar uma capa centrada na exposição do corpo masculino, pode ser vista na edição 43 (1999), que traz como assunto principal o "Abuso policial".

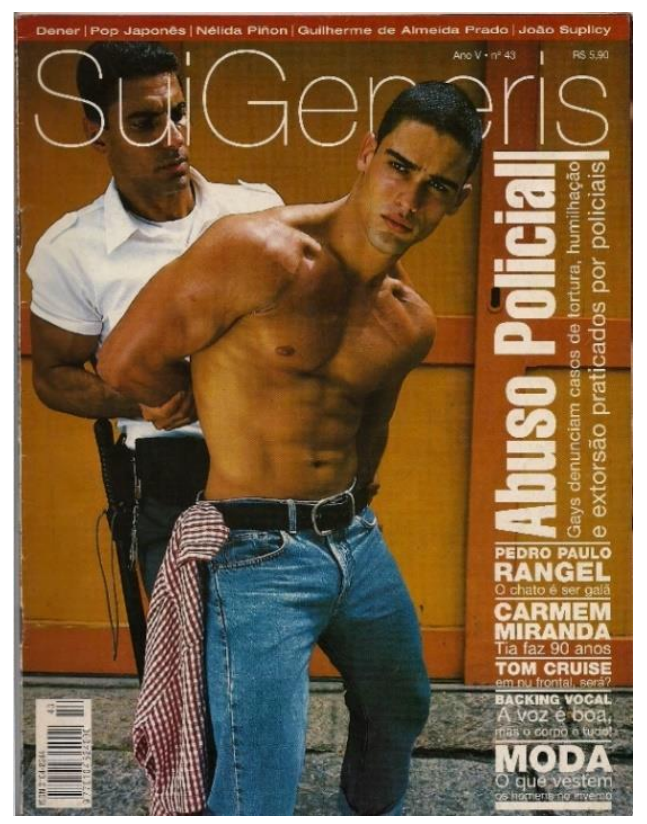

Figura 6 - Sui Generis, n. 46

Fonte: o autor 


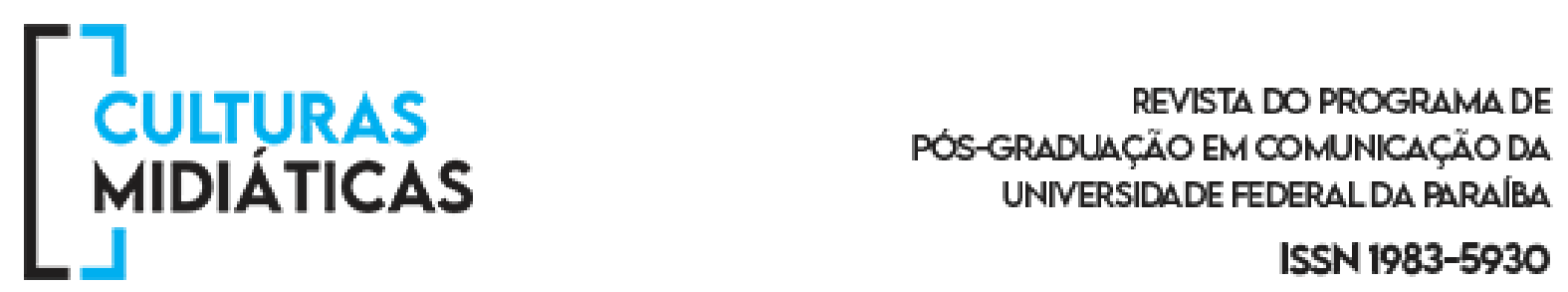

A disposição dos dois modelos que compõem a cena reforça sua dimensão erótica. A "vítima", em primeiro plano, está sem camisa, exibindo o torso definido, com veias nos braços e ombros em evidência, um corpo que se enquadraria no padrão "musculoso". A disposição corporal e o órgão sexual, que não aparece desnudo, mas se destaca no centro da composição reiterado pela calça jeans justa, reforçam mais uma vez uma performatização da virilidade. Já o outro modelo, o "policial", é igualmente musculoso, e a posição de imobilizar a "vítima" faz os músculos do braço direito serem ressaltados. O modo como os dois corpos interagem reitera o caráter performado da imagem, ou seja, uma maior valorização do contato entre os corpos dos dois homens como cena erótica do que uma imagem de representação de violência que servia de temática para a reportagem. O cassetete, presente como indumentária, novamente se desloca de símbolo de repressão policial para o domínio do erótico.

Não obstante os exemplos analisados até aqui, o corpus também revela que algumas capas buscavam explorar ou jogar com as fronteiras em que as masculinidades podiam ser representadas ou forjadas, como exploramos na próxima seção.

\section{OUTRAS MASCULINIDADES SÃO POSSÍVEIS?}

A edição 6 (outubro de 1995) retrata o ator André Gonçalves, que na época encarnava o personagem homossexual Sandrinho no programa que tradicionalmente possui a maior audiência da televisão brasileira, a telenovela do horário das "oito" (Figura 7). Se, numa análise intertextual, o ator era considerado um galã em ascensão, a personagem destacavase, como enfatizavam os textos do editorial e da reportagem, pelo mérito de apresentar ao público em geral um "gay normal", fora do estereótipo da "bicha" cômica das telenovelas até então. Entendemos que esta capa, porém, permite explorar fronteiras, limites e reapropriações de gênero, de masculinidades e feminilidades interrelacionadas com mais complexidade do que o discurso verbal da reportagem (e do próprio personagem de TV), ou da linha editorial defendida pela revista em um plano mais geral. 

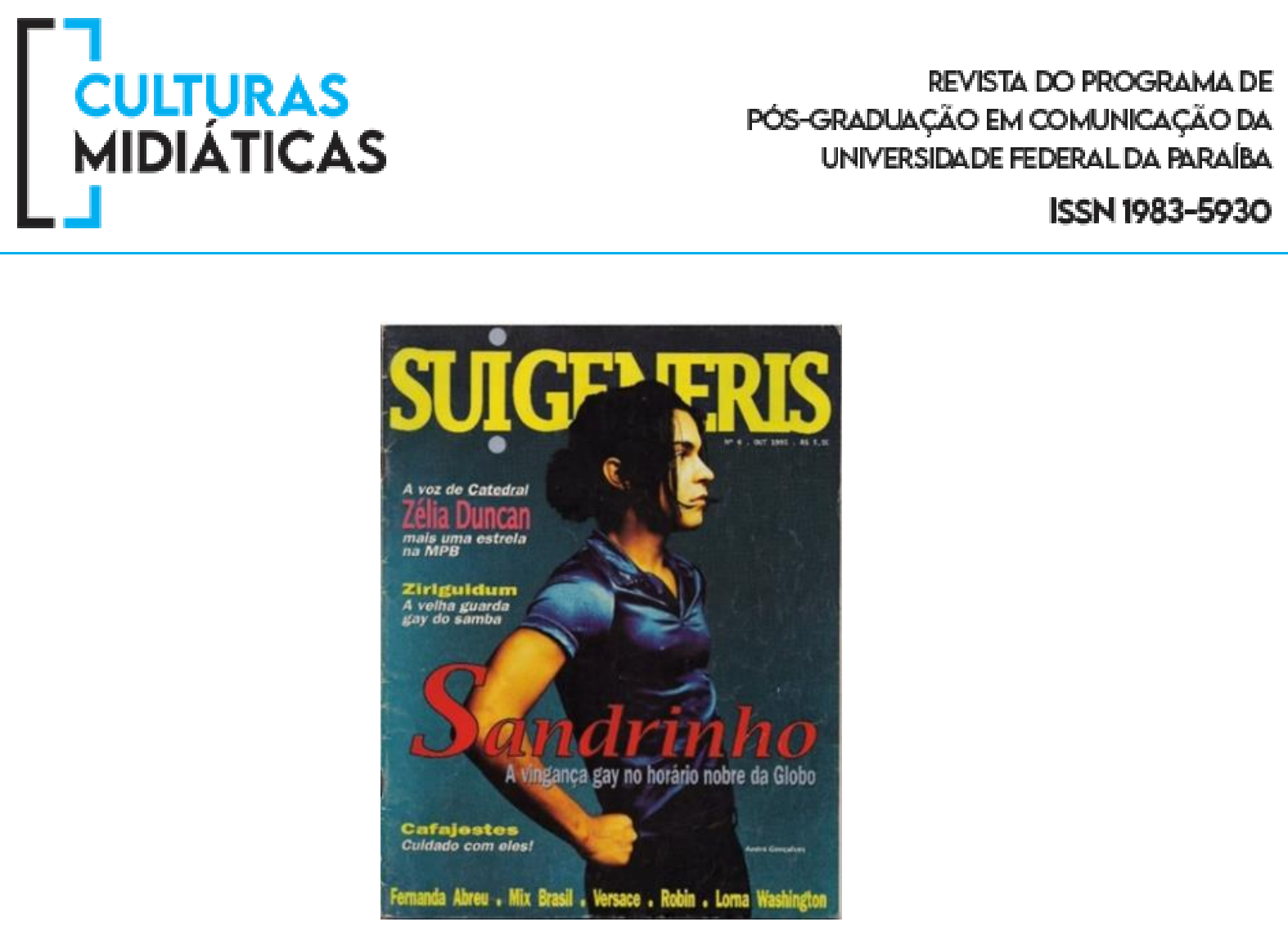

Figura 7 - Sui Generis, n. 6 Fonte: o autor.

A composição está centrada num jogo entre masculinidade e feminilidade, ancorado entre signos femininos (roupas, cabelo, a pose geral realçada no perfil) e masculinos (certa virilidade reforçada pela expressão séria do ator, a firmeza da mão quando segura a cintura, o punho fechado). Seu corpo não se encaixa no padrão do modelo "Barbie" de músculos hipertrofiados ou de uma hipervirilidade, sua masculinidade apareceria em detalhes de uma cena montada para destacar no plano mais geral uma ambiguidade, e o corpo é destacado pela luz, bíceps e peitoral que se marcam numa camisa justa de corte tradicionalmente associada como peça de roupa feminina.

Cabe pensar a presença do termo "gay" em duas chamadas: "vingança gay" e "a velha guarda gay", margeando o corpo do ator. É importante perceber que isso se dá, num contexto mais geral, fortemente marcado pela política de valorização identitária do (homem) "gay assumido" em Sui Generis. Podemos dizer que a performatização de "Sandrinho"/André Gonçalves naquela imagem coloca em posição de deslocamento o próprio discurso predominante na linha editorial da revista, de uma sexualidade gay calcada na normalidade/naturalidade/respeitabilidade e, em geral, masculina ("não-afeminada"), 


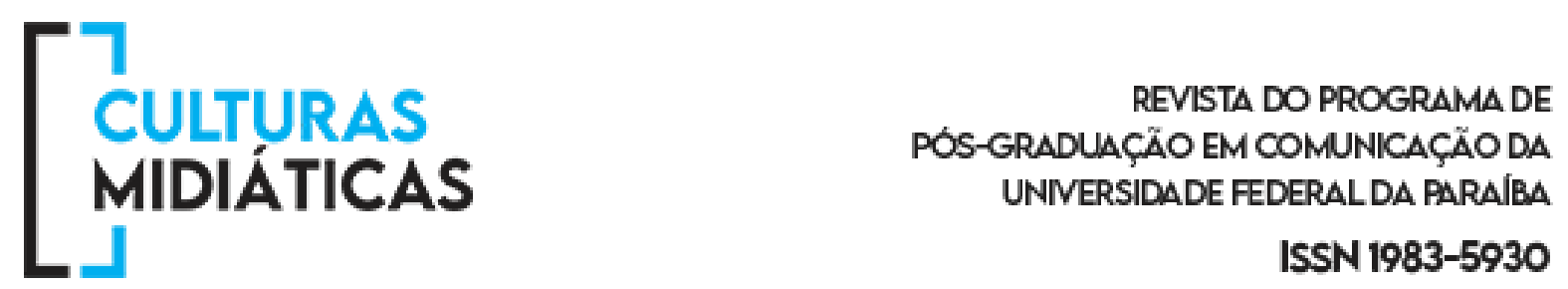

jogando entre uma abertura e uma reiteração das representações tradicionais da masculinidade.

"Masculino ou feminino" foi o tema da edição 23 (Figura 8), destacando que a "Nova androginia rompe os limites dos sexos". Há nesta capa uma vinculação direta entre androginia e o universo moda, algo reiterado pela presença do termo "nova" na chamada. Dois corpos abraçados são retratados. A modelo, à esquerda, destaca-se pela cabeça raspada, como se isto sugerisse a "ruptura" ou reelaboração dos limites do feminino (na chamada, usa-se o termo "sexos"). O rosto levemente para cima reforça a assertividade do olhar. Já o modelo aparece com o cabelo quase na altura dos ombros, com um corte bem trabalhado, compondo um look considerado "moderno", algo retratado constantemente nos editoriais de moda da própria revista. Também com uma mirada assertiva ao leitor, temos um corpo sem pelos e mais magro do que aqueles habitualmente retratados em capas de outras ediçõos.

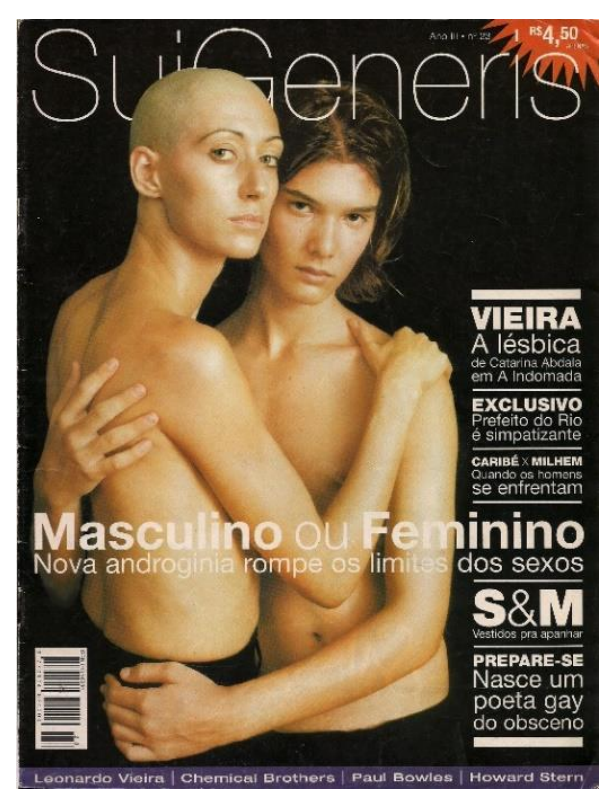

Figura 8 - Sui Generis, n. 23

Fonte: o autor. 


\section{[CuLTURAS MIDIÁTICAS

que esta "não deve e não pode ser reduzida ao corpo do homem e a seus efeitos". As masculinidades femininas costumam serem vistas como "as sobras depreciadas da masculinidade dominante, com a finalidade de que a masculinidade dos homens possa aparecer como a verdadeira", mas, "longe de ser uma imitação da virilidade, a masculinidade feminina, na realidade, nos dá pista de como se constrói a masculinidade como tal"' (Ibid., p. 23).

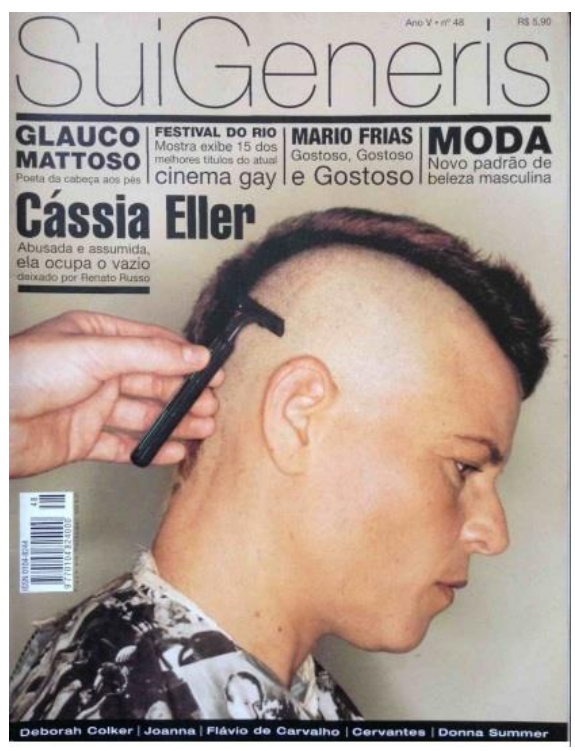

Figura 9 - Sui Generis, n. 48.

Fonte: o autor

Em que medida a capa com esta cantora lésbica "abusada e assumida" pode revelar e pôr em conflito essa performatização das masculinidades? Cássia Eller está de perfil e diferentemente das outras capas analisadas, não mira diretamente o leitor/a. A cena sugere a captura de um instante aparentemente banal, cortar o cabelo. Mas o corte é um moicano, o instrumento é um aparelho de barbear simples, ambos comumente associados ao masculino. A imagem oscila entre o registro de um ato em consonância com a personalidade pública descrita ("abusada") e uma expressão compenetrada, de introspecção. 
Entendemos que a escolha vai além da mera substituição do homem (gay ou hétero, assumido ou não, predominante nas capas de Sui Generis) por uma mulher lésbica, mas que há, aqui, uma performatização que desvela a própria naturalização da masculinidade tanto como propriedade dos homens habitualmente retratados nas capas da revista como do leitor, idealmente projetado como preferencial. A "lésbica abusada e assumida" é também aquela que tem a atitude de assumir aquele espaço editorial. A leitora projetada como "lésbica" seria não apenas distinta ou uma parcela menor do número total de leitores da revista, mas uma leitora com potencial de revelar e questionar o modelo prevalecente, colocando, assim, justamente a masculinidade como construção a ser interrogada ou disputada. Daí, chamamos a atenção para como as demais chamadas textuais da capa parecem restituir ou se reconectar com os leitores hegemônicos (homens), tentando manter aquele pacto editorial: "padrão de beleza masculina", "cinema gay", o ator presumidamente hétero "gostoso, gostoso e gostoso" funcionam como uma lembrança a "eles" de que Sui Generis ainda era a "sua" revista.

Chegamos à análise da última edição, a de número 55 (Figura 10), quando a revista encerrava suas atividades já no ano 2000, depois de um grande esforço em se manter como empreendimento editorial, algo que atravessou a história de Sui Generis mesmo nos momentos em que havia uma euforia com a expansão de um mercado de consumo centrado em "gays, lésbicas e simpatizantes" nos anos 1990. O texto editorial daquele exemplar não faz menção específica à escolha por aquela capa: o editor e proprietário da revista registra apenas que está contente por estampar aquela imagem. Busca-se representar tal sentimento a partir do retrato de um modelo jovem, com um largo sorriso. 

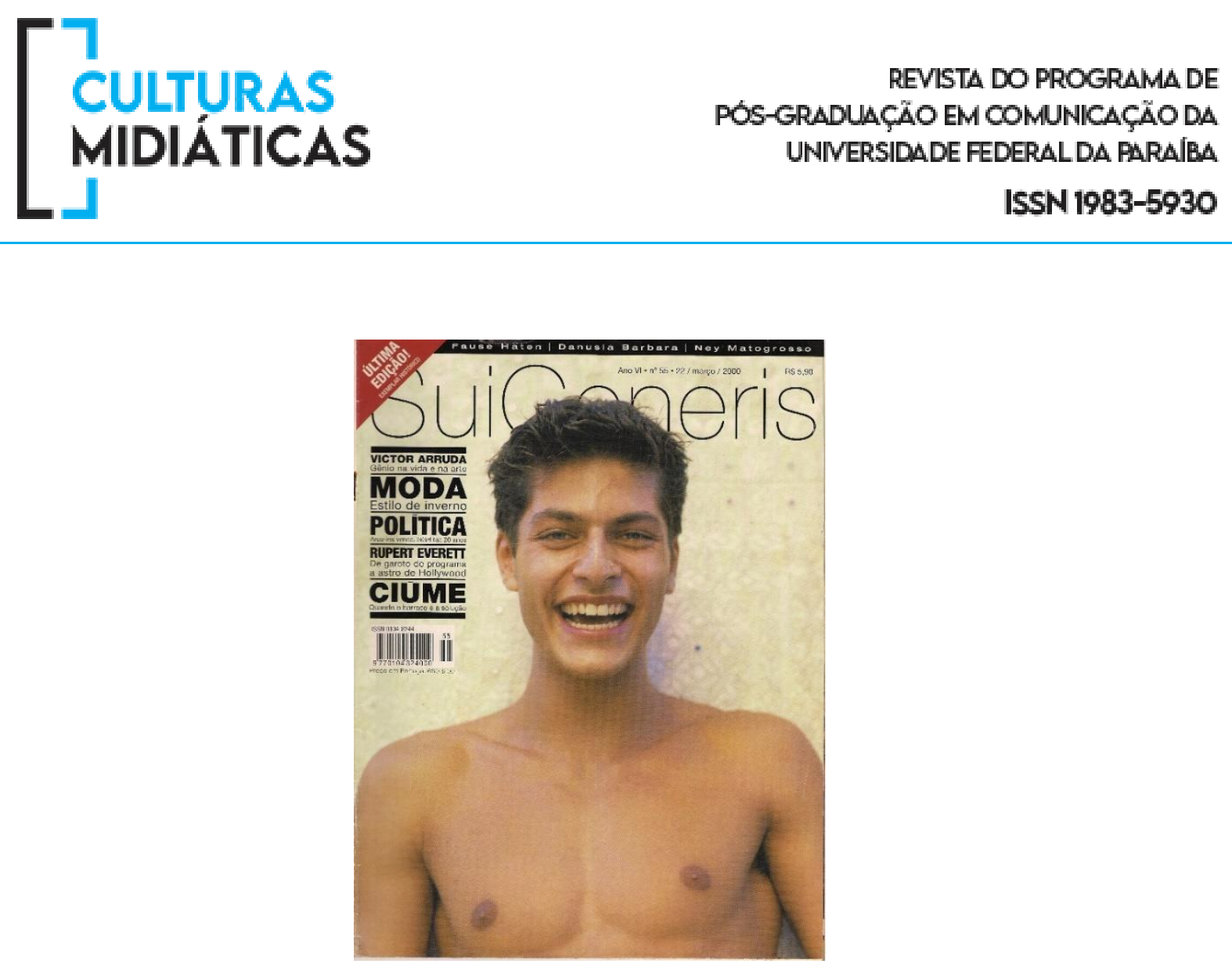

Figura 10 - Sui Generis, n. 55

Fonte: o autor.

Desse modo, busca-se ressignificar o encerramento da revista como algo positivo, dissociado de valores como frustação, tristeza etc. Isso converge para o projeto editorial que nasceu buscando elaborar uma nova imagem para as homossexualidades no Brasil da época. Antepondo-se à ideia de fim, a juventude é recuperada discursivamente nessa composição, ao trazer valores que costumam ser a ela valorados, de fim de um ciclo, mas de abertura ou transição para uma nova fase ou etapa de vida, de algo que ainda não se concluiu.

O corpo do modelo retratado na última edição analisada em nosso corpus, o derradeiro exemplar de Sui Generis, é desprovido de qualquer acessório, encarna um corpo em formação, em transição, com traços que serão desenvolvidos no futuro, mesmo que implique em cair em determinados padrões (magro, mas não uma "Barbie", delineado, mas não excessivamente musculoso etc.). Pode-se, naquela síntese, pinçar outros referentes que atravessaram a linha editorial nos cinco anos de existência de Sui Generis, como um corpo 
saudável (representado aqui pela pele bronzeada), estilo de vida (o corte de cabelo, o garoto de praia da zona sul carioca ou de outras cidades brasileiras...). Mas também pode ser visto como tentativa de sintetizar, num registro poético, uma homenagem da redação à própria história da revista (uma etiqueta na marquem esquerda superior registra a última edição como "Exemplar Histórico"), do esforço de ter tentado mantê-la funcionando como projeto jornalístico no campo de uma imprensa gay e do jornalismo informativo/cultural mais amplo.

\section{CONSIDERAÇÕES FINAIS}

Ao olharmos a capa da última edição de Sui Generis, sem muitos elementos que não seja o próprio corpo do modelo, encontramos uma economia de símbolos que, ao se centrar no retrato de um jovem desconhecido, torna-se expressiva, na medida em que pode oferecer uma mirada tanto das contínuas reiterações e reificações de modelos estabelecidos de masculinidades e de ser "gay" propagados pela revista, como dos anseios, das expectativas, dos esforços, das alegrias e, não menos importante, do mérito de se lançar e manter, entre erros e acertos, limites e contradições, um produto jornalístico que investiu na ideia de que poderia encarnar um projeto "singular", de capturar e (re)elaborar as homossexualidades "anunciadas" naquele fim de século.

Nesta investigação, buscamos identificar a complexidade das masculinidades performadas numa publicação de um gênero editorial segmentado, geralmente situado como "imprensa gay”. A partir da leitura crítica de nosso corpus, pudemos explorar exemplos em que prevalecem a reiteração de masculinidades tradicionais ou hegemônicas, com a performatização de atributos como a virilidade, a força, o papel ativo de controle nas cenas eróticas encenadas ali etc. Cabe ressaltar que, mesmo numa revista "assumidamente" endereçada a uma audiência (predominantemente) gay, lésbica, ou "simpatizante", recorriase à estratégia de estampar capas com homens que se diziam ou eram conhecidos 
publicamente como heterossexuais ou que, estando naquele espaço editorial, reiteravam verbal ou imageticamente atributos associados a uma masculinidade mais tradicional.

Destacamos, porém, que mesmo em alguns casos em que prevalece tal valorização de padrões de uma masculinidade hegemônica, há certa abertura para jogar com os códigos e limites dessa masculinidade. É o caso da capa estampada por um ator de televisão à época, em que ao mesmo tempo se reafirmava a tradicional identidade do "bofe" e se valia de códigos (trajes, cenário, postura corporal etc.) que, se não subvertiam certo padrão de masculinidade, abria outras possibilidade de apropriação pela audiência (gay).

Nosso objetivo não foi apenas "denunciar" a reiteração performática de masculinidades hegemônicas, uma vez que reconhecemos a possibilidade de múltiplas leituras dessas capas, procuramos também explorar exemplos que possibilitavam, em nosso entendimento, abrir criticamente o debate sobre as masculinidades no plural, com seus limites e contradições na combinação de imagens e textos. Assim, na análise da capa estampada por uma cantora lésbica "assumida", preferimos dar ênfase às eventuais disputas sobre conquistas e manutenções das masculinidades como domínio duplamente privilegiado (como dimensão editorial valorada na revista e como construto sociocultural situadas em relação às feminilidades e também às masculinidades não-hegemônicas), a atravessar a elaboração de uma revista para "gays, lésbicas e simpatizantes" mas que, cabe reforçar, era majoritariamente pautada e projetada para o leitor gay masculino.

A leitura que oferecemos está longe de ser definitiva, uma vez que as masculinidades ali performadas também eram e ainda são disputadas por leitores e leitoras, jornalistas, investigadores acadêmicos. Assim, fundamentalmente buscamos aqui ampliar a compreensão de uma parte singular da história de nossa imprensa (gay, mas também da imprensa brasileira, se olharmos para o todo) e de uma época crucial para as homossexualidades e as vidas LGBTs no Brasil, mas igualmente de pensar nas armadilhas e complexidades que as questões acerca das masculinidades, gênero e sexualidade seguem a nos desafiar, vinte anos depois de Sui Generis ir às bancas de revista pela última vez. 


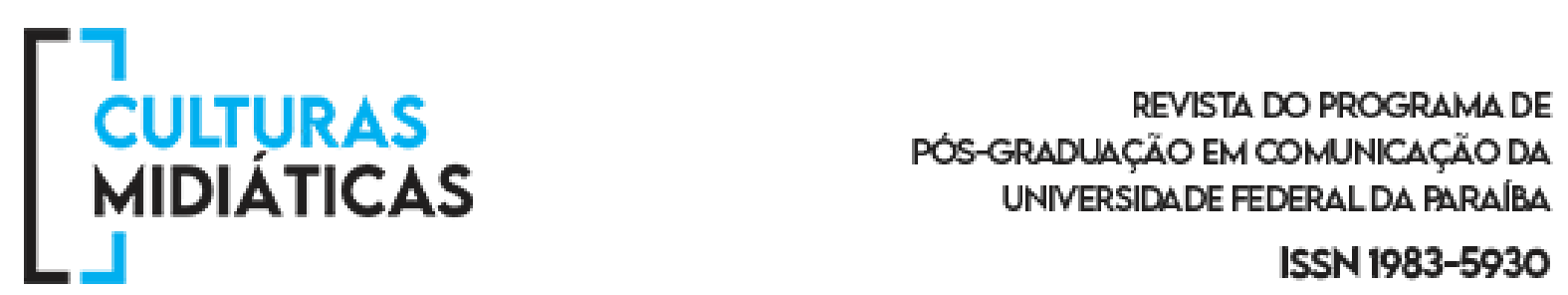

\section{REFERÊNCIAS}

BARTHES, Roland. A câmara clara: nota sobre a fotografia. Rio de Janeiro: Nova Fronteira, 2015.

BUTLER, Judith. Problemas de gênero: feminismo e subversão da identidade. $10^{a}$ ed. Rio de Janeiro: Civilização Brasileira, 2016.

CONNEL, Robert W.; MESSERSCHMIDT, James W. Masculinidade hegemônica: repensando o conceito. Estudos Feministas, 21(1), Florianópolis, jan/abr 2013.

DE LAURETIS, Teresa. A tecnologia do gênero. In: HOLLANDA, Heloísa Buarque de. (Org). Tendências e impasses: o feminismo como crítica da cultura. Rio de Janeiro: Rocco, 1994.

FEITOSA, Nelson. Editorial. Sui Generis, n.1, p. 4, janeiro 1995.

AUTOR, abril 2018.

FOUCAULT, Michel. História da sexualidade I: a vontade de saber. Rio de Janeiro: Edições Graal, 1999.

FRY, Peter. Para inglês ver: identidade e política na cultura brasileira. Rio de Janeiro: Jorge Zahar Ed., 1982.

GONTIJO, Fabiano. O Rei Momo e o arco-íris: homossexualidade e carnaval no Rio de Janeiro. Rio de Janeiro: Ed. Garamond, 2009.

HALBERSTAM, Judith. Masculinidad femenina. Barcelona/Madrid: Editorial Egales, 2008.

KIMMEL, Michael. Los estudios de la masculinidad: uma introdución. In: CARABÍ, Àngels; ARMENGOL, Joseph M. (eds). La masculinidad a debate. Barcelona: Icaria Editorial, 2008.

LEDDICK, David. The male nude. Colônia: Taschen, 2018.

MONTEIRO, Marko Synésio Alves. Masculinidades em revista: um estudo de VIP Exame, Sui Generis e Homens. Dissertação. Mestrado em Antropologia Social (Unicamp). Campinas, 2000. 


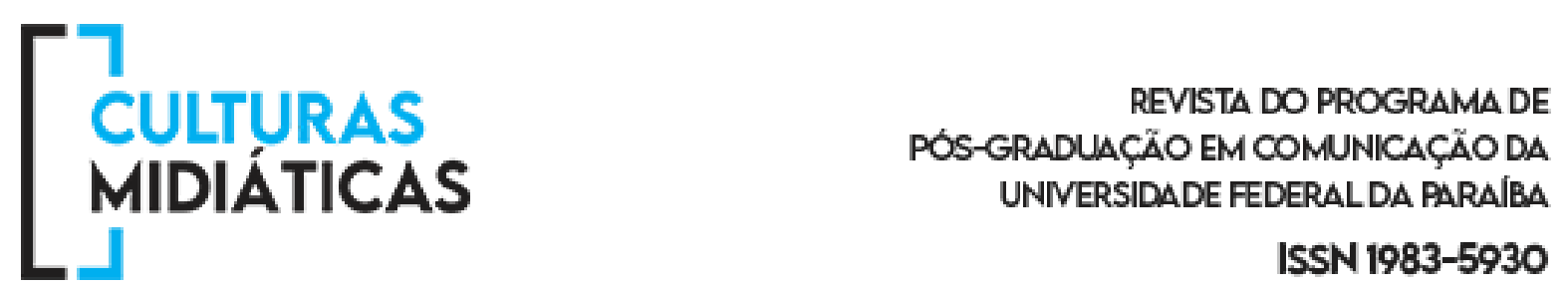

OLIVA, Jesús Martínez. Miradas transversales de la fotografía de desnudo masculino a la Antigüedad Clásica. Congreso Internacional" Imagines", La Antigüedad en las Artes escénicas y visuales: Universidad de La Rioja, Logroño 22-24 de octubre de 2007.

PACHECO, Leonardo Turchi. Futebol, masculinidade e a "amizade sem limites". Ponto Urbe [Online], 14, 2014. Disponível em: < http://journals.openedition.org/pontourbe/1450\%20;\%20DOI\%20:\%2010.4000/pontourb e.1450>. Acesso em 14 nov 2019.

PARKER, Richard. Abaixo do Equador: culturas do desejo, homossexualidade masculina e comunidade gay no Brasil. Rio de Janeiro: Record, 2002.

SIMÕES, Júlio Assis; FACCHINI, Regina. Na trilha do arco-íris: do movimento homossexual ao LGBT. São Paulo: Editora Perseu Abramo, 2009.

SIMÕES, Júlio Assis; FRANÇA, Isadora Lins. Do "gueto" ao mercado. In: Homossexualismo em São Paulo e outros escritos. São Paulo: Editoria Unesp, 2005.

TRAQUINA, Nelson. Teorias do Jornalismo: a tribo jornalística - uma comunidade interpretativa transnacional. Florianópolis: Insular, 2008.

TREVISAN, João Silvério. Devassos no paraíso: a homossexualidade no Brasil, da colônia à atualidade. Rio de Janeiro: Record, 2000.

VAZ, P. B. F.; TRINDADE, V. C. Capas de revistas e seus leitores: um novo texto em cartaz. In: TAVARES, Frederico de Mello B.; SCHWAAB, Reges. (Org.). A Revista e seu Jornalismo. Porto Alegre: Penso, 2013, v. 1, p. 221-234.

WOODWARD, Kath. Boxing, masculinity and identity: the "I" of the tiger. Londres: Routledge, 2007. 